\title{
Promoção da saúde de adolescentes em instituição de acolhimento: desafio para o enfermeiro
}

\author{
Promoting Adolescent Health in a Host Institution: A Challenge for Nurses \\ Promoción de la Salud de Adolescentes en Institución de Acogida: Desafío para el \\ Enfermero
}

Alires Morozini Dias ${ }^{1 *}$, Sandra Ost Rodrigues ${ }^{1}$, Claudete Moreschi ${ }^{1}$, Patrícia Bitencourt Toscani Greco'.

\section{RESUMO}

Objetivo: Desenvolver ações de promoção da saúde com adolescentes que estão em situação de acolhimento institucional em um município do interior do Rio Grande do Sul. Relato da experiência: Tratase de um relato de experiência acerca de uma Prática Assistencial que se realizou durante o mês de setembro, outubro e novembro de 2018 em uma instituição de acolhimento para meninas e meninos em um município localizado na região central do Rio Grande do Sul. Os encontros foram realizados semanalmente e de acordo com a disponibilidade e aceitação por parte da equipe e dos participantes, que foram cinco adolescentes meninas e um menino. A faixa etária variou entre doze e dezoito anos e o período em que estavam institucionalizados, de dois a oito anos. As atividades desenvolvidas envolveram diversas temáticas e ações, como: Autoestima, DSTs, passeios, atividade física, entre outras. Considerações finais: A partir dessa vivência, foi possível perceber a importância do enfermeiro nas instituições de acolhimento proporcionando um cuidado continuado, pois a proximidade vivida pelos adolescentes nesse contexto é permeada pela reciprocidade dos vínculos estabelecidos.

Palavras-chaves: Saúde do adolescente institucionalizado, Promoção da Saúde, Enfermagem.

\begin{abstract}
Objective: To develop health promotion actions with adolescents who are in an institutional reception situation in a municipality in the interior of Rio Grande do Sul. Experience report: This is an experience report about an Assistance Practice that took place during the months of September, October and November of 2018 in a host institution for girls and boys in a municipality located in the central region of Rio Grande do Sul. The meetings were held weekly and according to availability and acceptance by the team and participants, who were five teenage girls and one boy. The age range varied between 12 and 18 years and the period in which they were institutionalized, from two to eight years. The activities developed involved several themes and actions, such as: Self-esteem, STDs, walks, physical activity, among others. Final considerations: Based on this experience, it was possible to perceive the importance of the nurse in the care institutions, providing a continuous care, since the proximity experienced by the adolescents in this context is permeated by the reciprocity of the established links.
\end{abstract}

Key-words: Institutionalized adolescent health, Health Promotion, Nursin.

\footnotetext{
${ }^{1}$ Universidade Regional do Alto Uruguai e das Missões Campus Santiago (URI), Santiago-RS.

*E-mail: alires-dias@hotmail.com
}

SUBMETIDO EM: 2/2019

ACEITO EM: $3 / 2019$

PUBLICADO EM: 7/2019 


\section{RESUMEN}

Objetivo: Desarrollar acciones de promoción de la salud con adolescentes que están en situación de acogida institucional en un municipio del interior de Rio Grande do Sul. Informe de experiencia:Se trata de un relato de experiencia acerca de una práctica asistencial que se realizó durante el mes de septiembre, octubre y noviembre de 2018 en una institución de acogida para niñas y niños en un municipio ubicado en la región central de Rio Grande do Sul. Los encuentros se realizaron semanalmente y de acuerdo con la disponibilidad y aceptación por parte del equipo y de los participantes, que fueron cinco adolescentes niñas y un niño. El grupo de edad varía entre doce y dieciocho años y el período en que estaban institucionalizados, de dos a ocho años. Las actividades desarrolladas involucraron diversas temáticas y acciones, como: Autoestima, ETS, paseos, actividad física, entre otras. Consideraciones Finales: A partir de esa vivencia, fue posible percibir la importancia del enfermero en las instituciones de acogida proporcionando un cuidado continuado, pues la proximidad vivida por los adolescentes en ese contexto está impregnada por la reciprocidad de los vínculos establecidos.

Palabras claves: Salud del adolescente institucionalizado, Promoción de la Salud, Enfermería.

\section{INTRODUÇÃO}

O Estatuto da Criança e do Adolescente (ECA) prevê no art. 98 medidas de proteção aplicáveis à criança e ao adolescente sempre que estes tiverem seus direitos ameaçados ou violados, seja por ação ou por omissão da sociedade ou do Estado, seja por falta, ameaça, abuso dos pais ou responsáveis, ou ainda devido à má conduta destes. Uma das medidas previstas na referida legislação é o acolhimento institucional (SOUZA FHO e BRITO LMT, 2015).

No Brasil segundo o Conselho Nacional de Justiça (CNJ) 47 mil crianças e adolescentes vivem em situação de acolhimento institucional. Situação essa de proteção "provisória e excepcional" que ocorre nos casos de abandono, negligência ou risco pessoal. Acontece por ordem judicial, que concede a guarda ao responsável pela instituição, o que não destitui a perda do poder familiar e só ocorre através de específico processo judicial (SENADO FEDERAL, 2013)

Além disso, o acolhimento institucional possui o papel de favorecer o desenvolvimento da criança/adolescente, ofertando cuidado e proteção, como também um contexto educativo. É imprescindível que a entidade de acolhimento não seja concebida como um local de exclusão, mas sim como espaço que proporcione $o$ crescimento de crianças e adolescentes que ali permanecem, independentemente do tempo (MACHADO VR, 2011).

Nesse sentido, Teixeira MB et.al (2014) refere que as ações de promoção da saúde possuem espaço privilegiado para o desenvolvimento de práticas com os que se encontram em ambiente de acolhimento institucional. Essas condutas devem ser voltadas para o empoderamento, busca pela equidade, comunicação e educação em saúde, de modo que o cuidado se torna ampliado e mais efetivo em suas estratégias e ações.

Dessa maneira a enfermagem possui um papel primordial para esse processo, pois é imprescindível que o cuidado dedicado às crianças e aos adolescentes seja orientado no sentido de oferecer um ambiente seguro e não desagradável e amedrontador. Além disso, reforça-se a importância que o pressuposto fundamental da criação das instituições de acolhimento é de poder fornecer um ambiente melhor do que aquele em que a criança se encontrava (CARVALHO CF, et al., 2015).

Diante disso, justifica-se o objetivo do desenvolvimento dessa Prática Assistencial, no sentido de compreender que o enfermeiro é um profissional fundamental no contexto da promoção da saúde e hábitos saudáveis nas instituições de acolhimento, uma vez que seu foco é a assistência integral e direta à saúde. Assim, é capaz de fortalecer o desenvolvimento de atividades como: Grupos de Saúde, consulta de enfermagem, encaminhamentos para serviço da rede, escuta qualificada, vínculo e convivência com o profissional da saúde e família. 
Sendo assim, o objetivo dessa Prática Assistencial foi desenvolver ações de promoção da saúde com adolescentes que estão em situação de acolhimento institucional em um município do interior do Rio Grande do Sul (RS). O presente estudo trata-se de um relato de experiência acerca de uma Prática Assistencial que se realizou durante o mês de setembro, outubro e novembro de 2018 em uma instituição de acolhimento para meninas e meninos em um município do interior do RS que está localizado na região central do estado.

A referida instituição está vinculada a Secretaria de Desenvolvimento Social com o apoio da Secretaria de Educação e da Saúde, com o objetivo de acolher meninas e meninos desde o nascimento até os 18 anos. A prática foi realizada semanalmente e de acordo com a disponibilidade e aceitação por parte da equipe e dos participantes, não intervindo na rotina do serviço. Os participantes foram cinco adolescentes meninas e um menino. A faixa etária variou entre doze e dezoito anos e o período em que estavam institucionalizados foi de dois a oito anos. Salienta-se que os tipos de atividades, a duração, datas e temáticas serão descritas especificamente a seguir.

\section{RELATO DE EXPERIÊNCIA}

No primeiro momento ocorreu uma visita ao local para que fosse possível conhecer a rotina da casa, horários dos adolescentes e iniciar a formação de vínculo. A partir de então juntamente com a coordenadora foi estipulado que o melhor dia para que ocorressem as práticas seriam as quartas-feiras no período da tarde, pois é o dia e horário em que se encontram mais adolescentes no espaço.

No primeiro encontro com os adolescentes, todos estavam presentes, houve uma apresentação das duas partes, foi tratado sobre a proposta de estar no local uma vez por semana ofertando atividades de promoção da saúde. Nesse instante também foi exposto sobre o que cada um gosta de fazer, como é a rotina na escola e no lar, a convivência entre eles na casa, além de ter sido abordado ideias de quais ações eles gostariam que fossem desenvolvidas nos encontros, oferecendo autonomia aos participantes e aproximando o máximo da realidade que eles vivenciam.

No segundo encontro participaram cinco adolescentes, foi ofertada uma atividade sobre autoestima. Foram distribuídas diversas peças de quebra-cabeça que ao montá-las formavam frases motivacionais, como por exemplo: "Não deixe que as pessoas te façam desistir daquilo que você mais quer na vida. Acredite. Lute. Conquiste e acima de tudo seja feliz." "Acredite mais nas suas capacidades, pois você é a única pessoa capaz de mudar o rumo da sua vida". Após o encaixe correto e leitura das frases as mesmas foram coladas e os adolescentes criaram um cartaz e chegaram ao acordo que este deveria ficar exposto no refeitório para uma visualização mais frequente.

Nesse instante foi debatido o tema respeito e preconceito e cada um mencionou o seu ponto de vista sobre o que era autoestima. Eles relataram que sofrem preconceito na escola que frequentam e consideram que tem a autoestima baixa, resultando em um isolamento social, quando referem "não ter amigos na escola".

A partir disso, tratou-se também da importância de valorizar as qualidades, e de mudar aquilo com o qual não se está satisfeito, começando pelos hábitos e rotina. A seguir uma das adolescentes, espontaneamente propôs a ideia de cada um citar uma qualidade do outro, essa ocasião foi possível observar uma maior autoconfiança, pois eram elogios que vinham dos colegas que convivem diariamente na casa. O clima foi de descontração e aproximação entre todos. Nesse dia, após a atividade proposta foi ofertado um lanche partilhado e solicitado pelos participantes que o próximo encontro fosse embasado em um filme.

Para o terceiro encontro foi apresentado o filme "PAIS E FILHAS" que tinha como tema drama em família. No momento devido às outras atividades que os adolescentes se encontravam, apenas dois participaram. $O$ filme trata de um pai que após a morte da sua esposa em um acidente, tenta criar sozinho a filha Katie, de cinco anos. O mesmo está com sua saúde mental abalada é e obrigado a se afastar dela. Vinte anos depois, já adulta, Katie estudante de psicologia, ajuda crianças com problemas e tenta superar os seus de infância.

Após a mostra do filme emergiram discussões sobre o tema e os problemas que se apresentaram no mesmo, além de os participantes mencionarem episódios que mais chamaram a atenção. Foi abordado o 
assunto família e a sua importância, cada adolescente comentou como enxergava a situação de estar institucionalizado naquele momento e o que esperavam para o futuro, além de mencionarem que sentem falta dos familiares, pois alguns encontravam-se no local há oito anos, fragilizando assim o vínculo com a família.

No quarto momento o assunto foi infecções sexualmente transmissíveis (IST) e gravidez na adolescência, segundo sugestão dos participantes. Nesse dia estavam todos os presentes. Foi apresentado um documentário produzido pelo Programa Profissão Repórter acerca do assunto gravidez na adolescência, vulnerabilidade das adolescentes frente a situação, dificuldades enfrentadas com estudo e trabalho entre outros. Na sequência foi discutido a temática. E após foi abordado o assunto IST que foi exibido em slides as principais doenças, sintomas, e tratamento. A participação dos adolescentes foi bastante ativa no sentido de mostrarem interesse pela temática e pelo autocuidado. Também foi possível sanar dúvidas e questionamentos a respeito do tema a partir das suas vivências

Ainda, nesse contexto, foram expostos para conversação os métodos contraceptivos, exibido o preservativo feminino e masculino e salientado a sua utilização correta e regular, pois representa o único método seguro e eficaz na prevenção das IST e gravidez. Ao final do encontro foi degustado um café interativo com música e extroversão. A partir do desejo deles, o quinto encontro se deu em uma Universidade, para conhecerem os laboratórios de anatomia e de enfermagem. Participaram do passeio quatro adolescentes, que foram recebidos no laboratório de anatomia por uma professora responsável pelo local. A mesma exibiu, explicou e possibilitou que os materiais anatômicos fossem manuseados.

$\mathrm{Na}$ visita ao laboratório de enfermagem fomos recebidos pela bolsista do local, que mostrou os materiais e explicou para que eram utilizados, como por exemplo, aparelho de pressão, estetoscópio, espéculo entre outros. Foi possível demonstrar nas réplicas como é realizado o autoexame das mamas, além do exame de Papanicolau. Observou-se a motivação dos adolescentes em estar na universidade, visto a relevância social da mesma no município, sentindo-se incluídos e mostrando-se interessados e curiosos em todos os momentos da visita, além de terem suas dúvidas sanadas quando solicitado.

O sexto encontro ocorreu de acordo com a vontade dos adolescentes que solicitaram a prática de uma atividade física que envolvesse dança. Desse modo foi convidado para o desenvolvimento dessa prática um acadêmico do curso de Educação Física da Universidade, que trouxe o ritmo da zumba. No primeiro momento, foi realizado um alongamento e esclarecimento sobre o ritmo escolhido, seus benefícios e a possibilidade dos adolescentes estarem participando de um grupo de zumba que acontece no município semanalmente.

O acadêmico levou as músicas de acordo com o ritmo da zumba e logo após deu-se o início a prática que durou mais ou menos uma hora e meia. Nesse encontro participaram quatro adolescentes que demostraram satisfação, dedicação e euforia em estarem desempenhando aquela atividade física, ao final relataram sentimento de bem-estar. Organizou-se no sétimo encontro um momento especial em um salão de beleza a pedido dos adolescentes que gostariam de ter uma tarde de cuidados com a sua aparência. Participaram desse encontro três adolescentes, que no local fizeram unha, cabelo e maquiagem. Após estarem prontos contou-se com a participação de um fotógrafo que fez diversas fotos individuais e coletivas dos adolescentes, as quais foram impressas e oferecidas aos adolescentes como uma lembrança do momento.

Foi possível observar uma melhora da autoestima dos participantes, que se mostraram descontraídos, colaborativos e muito alegres naquele momento, o que o tornou prazeroso, conforme relatado por eles. Foram ofertados aos adolescentes os serviços do salão gratuitamente quando desejarem.

\section{DISCUSSÃO}

Nesse sentido, Penna LHG et. al (2012) afirmam ser de grande importância que às ações desenvolvidas nas instituições de acolhimento atinjam o comportamento dos adolescentes em seu processo de sobrevivência e de seus mecanismos de enfrentamento diante das situações adversas. Desse modo, as ações de promoção da saúde devem ser estabelecidas em conjunto com os adolescentes, tendo em vista atingir a conquista de inserção social e cidadania. 
Desse modo Rodrigues AL et. al (2014) referem que o fato dos adolescentes em situação de acolhimento manifestar uma maior percepção de preconceito pode estar relacionado à própria condição de institucionalização, que lhes confere uma identidade social, marca-os como diferentes perante a sociedade e os tornam, potencialmente, alvos de preconceito. Por isso pode-se compreender a importância da promoção da saúde nas instituições de acolhimento, como estratégia para um melhor enfrentamento ativo dos adolescentes além de poder estar mediando o impacto do preconceito percebido sobre a autoestima dos mesmos.

Segundo Cavalcante LIC et. al (2010) do ponto de vista do adolescente institucionalizado, os efeitos gerados pela inexistência ou fragilidade dos vínculos familiares já estabelecidos, podem ser agravados pela permanência prolongada em ambiente institucional. Os efeitos dessa experiência sobre a formação da identidade e o sentimento de segurança emocional podem deixar o adolescente ainda mais vulnerável a doenças físicas e psíquicas, dificuldades de relacionamento de convívio social, entre outros danos.

Por isso destaca-se a importância da qualificação dos profissionais que atuam nesses locais e de toda a rede socioassistencial para melhor atender quem está institucionalizado, assim como as condições estruturais existentes nestes serviços que precisam ser aperfeiçoados, visando o encurtamento do período de acolhimento institucional. Portanto, os profissionais que desenvolvem grupos de educação em saúde envolvendo adolescentes precisam acolher e envolver esses indivíduos de forma dinâmica possibilitando o conhecimento na troca de informações, pois não basta apenas informar. É preciso, sobretudo, conscientizar o adolescente dos riscos aos quais está exposto e de como evitá-los. Por isso, a importância do enfermeiro, no sentido de poder contribuir para o empoderamento desses indivíduos e consequentemente, na efetivação de ações que possibilitem a redução da vulnerabilidade desses adolescentes às DST e gravidez não planejada (DIAS FLA et. al 2010).

Além disso, a participação do enfermeiro nas instituições de acolhimento deve proporcionar ao público adolescente um cuidado baseado na educação e na problematização, possibilitando desse modo um melhor amadurecimento e reflexão dos mesmos sobre saúde sexual. Desse modo profissional e adolescente podem juntos buscar possíveis soluções para problemas baseados nesse contexto (PENNA LHG et.al 2012).

Desse modo, destaca-se a importância de promover práticas educativas, para que essas ajudem no desenvolvimento de competências para o adolescente. Aumentando assim o conhecimento dos mesmos sobre métodos contraceptivos e doenças sexualmente transmissíveis, bem como melhorar a capacidade de comunicação para uma melhor expressão de suas opiniões assertivamente (PEREIRA S, VILAÇÃ T, 2015).

Dentro desse processo de ensino aprendizagem a motivação torna-se primordial, pois a partir dela podese desenvolver a criatividade de forma que se desperte o interesse do adolescente. Por isso deve-se auxiliar e traçar planos que favoreçam o avanço motivacional voltado para os estudos. Consequentemente é crucial para qualquer profissional que atua no processo de ensino, compreender fatores que podem interferir neste seguimento e a partir disso utilizar técnicas efetivas de intervenção que possam motivar e aprimorar 0 processo de aprendizagem (CAMPEIZ AF, ARAGÃO AS, 2013).

Nessa perspectiva, os efeitos da atividade física na adolescência enfatizam benefícios proporcionados à promoção da saúde e prevenção de doenças. Sendo assim, há uma grande preocupação em incentivar adolescentes desde cedo a desenvolverem estilos de vida saudável. Os jovens devem ser claramente informados a respeito dos benefícios relacionados à saúde, a curto e longo prazo, da prática regular de atividades físicas, assumindo responsabilidade direta pelo desenvolvimento dos seus próprios comportamentos de saúde (SILVA PVC, COSTA AL, 2011).

Assim, destaca-se a influência da autoimagem diretamente relacionada ao bem-estar do adolescente, não apenas na adolescência, mas em qualquer fase da vida e está diretamente relacionada ao o nível de felicidade do indivíduo. Na adolescência faz-se necessário trabalhar os valores de cada um, respeitando cada qual com suas diferenças e peculiaridades. Dessa maneira torna-se indispensável o papel do enfermeiro, pois compete a esse o papel de propulsor de melhorias no estado biopsicossocial do indivíduo, nas diversas esferas sociais e para isso, a autoestima deve ser ponto fundamental de seu trabalho (BRAGA JR, ALVES JPP, 2015). 


\section{CONSIDERAÇÕES FINAIS}

A partir dessa vivência, foi possível perceber a importância do enfermeiro nas instituições de acolhimento proporcionando um cuidado continuado, pois a proximidade vivida pelos adolescentes nesse contexto é permeada pela reciprocidade dos vínculos estabelecidos. Por isso essa prática assistencial permitiu um novo olhar para cada um desses indivíduos, além de contribuir efetivamente no desenvolvimento de ações de promoção da saúde, que auxiliaram no enfrentamento de situações que podem ir além do domínio social e cultural, auxiliando os adolescentes na superação e autonomia para conduzirem suas vidas.

\section{REFERÊNCIAS}

1. BRAGA JR. ALVES JPP. Autoestima na adolescência e a influência sobre o bem-estar biopsicossocial. FDeportes.com, Revista Digital, 2015; 20(209).

2. CAMPEIZ AF. ARAGÃO AS. Adolescentes, autoestima e o processo de ensino-aprendizagem. Revista lberoAmericana de estudos em educação. 2013, 8(3); 1982-558.

3. CARVALHO CF. RAZERA J. FALCKE KRH. Acolhimento institucional: considerações sobre a forma como o cuidado subjetivo se apresenta no cotidiano de trabalho dos educadores sociais. Aletheia, 2015; 47(48): 51-63.

4. CAVALCANTE LIC, SILVA SSC, MAGALHÃES CMC. Institucionalização e reinserção familiar de crianças e adolescentes. Revista Mal-estar e Subjetividade, 2010; 10(4): 1147-1172.

5. DIAS FLA, SILVA KL, VIEIRA FN, et. al. Riscos e vulnerabilidades relacionados à sexualidade na adolescência. Revista enfermagem UERJ, 2010; 18(3): 456-61.

6. MACHADO VR. A atual política de acolhimento institucional à luz do estatuto da criança e do adolescente. Serviço Social em Revista, 2011; 13(2): 143-169.

7. SILVA PVC, COSTA AL. Efeitos da atividade física para a saúde de crianças e adolescentes. Psicologia Argumento, $2011 ; 29(64): 41-50$.

8. SOUZA, FHO, BRITO LMT. Acolhimento institucional de crianças e adolescentes em Aracaju. Psicologia Clínica. $2015 ; 27(1): 41-57$.

9. PENNA LHG. FERNANDES SR. GUEDES RG. et. al. Concepção de profissionais de unidades de acolhimento sobre a maternidade em adolescentes abrigadas. Revista da Rede de Enfermagem do Nordeste, 2012; 13(1): 44-52.

10. PEREIRA S. VILAÇA T. Educação em sexualidade de mães adolescentes institucionalizadas num centro de apoio à vida. Revista Ibero-Americana de Estudos em Educação. 2015; 10(esp).

11. Revista de audiências públicas do Senado Federal. Ano 4 - № 15 - maio de 2013.

12. RODRIGUES AL, GAVA LL, SARRIERA JC, et. al. Percepção de preconceito e autoestima entre adolescentes em contexto familiar e em situação de acolhimento institucional. Estudos e pesquisa em psicologia, 2014; 14(2): 389407.

13. TEIXEIRA MB. CASANOVA A. OLIVEIRA CCM. et.al. Avaliação das práticas de promoção da saúde: um olhar das equipes participantes do Programa Nacional de Melhoria do Acesso e da Qualidade da Atenção Básica. Saúde debate, 2014; 38(esp): 52-68. 